\title{
Development of an immunofluorescence test for the serodiagnosis of herpes zoster ophthalmicus
}

\author{
P WALPITA,' S DAROUGAR,' R J MARSH, ${ }^{2}$ AND M COOPER
}

From the 'Institute of Ophthalmology, Judd Street, London WC1, and ${ }^{2}$ Moorfields Eye Hospital, London EC1

SUMMARY An indirect immunofluorescence test has been developed and evaluated for the serodiagnosis of herpes zoster ophthalmicus ( $\mathrm{HZO})$ by the detection of antivaricella zoster virus (VZV) antibody. The results show that, in patients with HZO, anti-VZV IgG antibody titre usually rises rapidly after onset. One hundred and seven of the 134 sera $(80 \%)$ from patients with a clinical diagnosis of $\mathrm{HZO}$ had an anti-VZV IgG titre of $\geqslant 256$, and IgM antibody at a level of 1 in 8 was present in six of them. In comparison only two of the 216 sera $(1 \%)$ from patients with a clinical diagnosis of ocular infections other than those caused by VZV had such IgG titres. It was concluded that, on the basis of results of a single sample of serum, it is possible to make a provisional diagnosis of $\mathrm{HZO}$ with a high degree of confidence.

Varicella-zoster virus (VZV) can affect any part of the eye with varying degrees of severity, producing rather a pleomorphic clinical picture. The clinical diagnosis of $\mathrm{HZO}$, when associated with typical skin lesions presents no problems. However, sometimes there are minimal or no skin lesions or there is an

Correspondence to Dr P Walpita, Institute of Ophthalmology, Judd Street, London WC1 9QS. atypical rash which may mimic that of herpes simplex virus (HSV). ' Hence a rapid and sensitive laboratory diagnosis is important in the differential diagnosis of these atypical cases.

Several laboratory tests are available for the diagnosis of VZV infections. Demonstration of viral antigens in clinical specimens is rapid, but it is useful only during the first few days of infection when

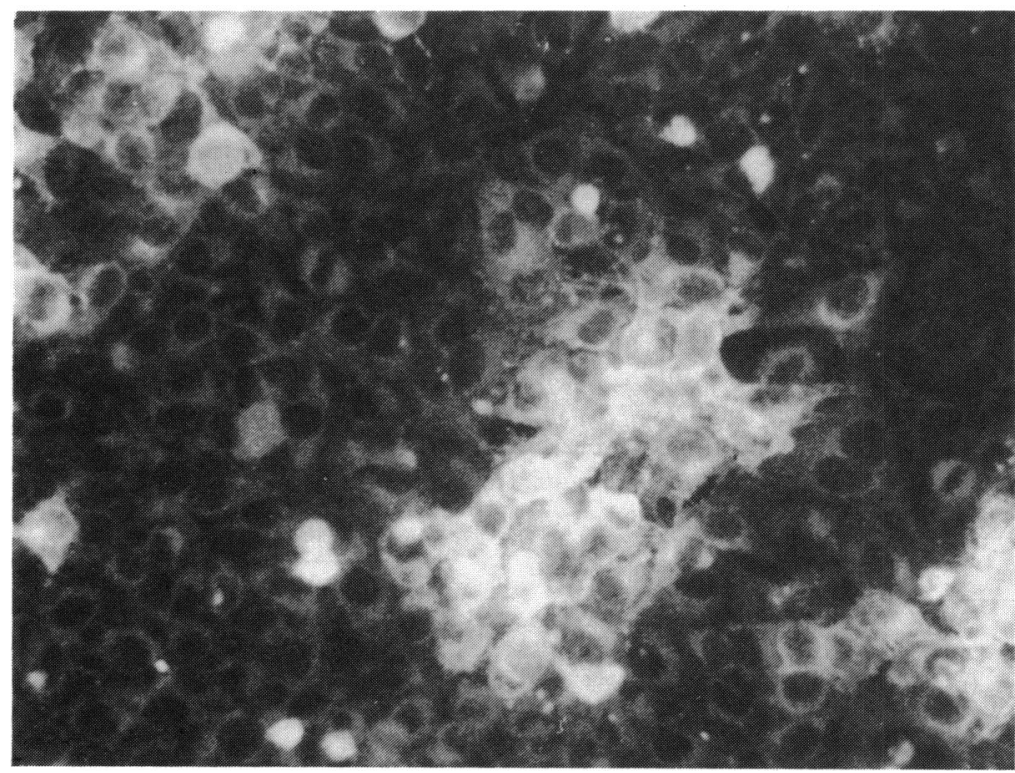

Fig. 1 Brightly fluorescing VZV infected cells growing as plaques in HeL a cell monolayer. (× 540). 
vesicles are present. ${ }^{2}$ Virus isolation in cell culture is a definitive means of diagnosis, but this is possible in only a few cell lines and only during the first few days of infection. Several serological tests are available, including immunofluorescence tests for the diagnosis of VZV infections, ${ }^{34}$ but none have been evaluated for the differential diagnosis of HZO.

We report the development of an immunofluorescence test for the serodiagnosis of $\mathrm{HZO}$ using a single sample.

\section{Patients, Materials, and methods}

\section{PATIENTS}

Sera were collected from patients attending the Zoster Clinic and Keratoconjunctivitis Clinic at Moorfields Eye Hospital in London and stored at $-20^{\circ} \mathrm{C}$ until examined. A total of 350 sera were collected from patients with $\mathrm{HZO}$, ocular HSV, and other ocular viral infections. All the sera were examined for anti-VZV IgG antibody. IgM was determined only in the sera from HZO patients. In addition, anti-HSV $1 \mathrm{IgG}$ titre were determined in a subsample of sera from the HZO patients by means of a microimmunofluorescence test. ${ }^{5}$

\section{Materials and methods}

Antigen preparation. A strain of VZV isolated from a case of chicken-pox (kindly supplied by the Virology Department, Institute of Child Health, London) was serially passaged in HeLa cells for antigen preparation. The infected monolayers prepared in flasks were trypsinised and resuspended in growth medium. The total number of HeLa cells per ml of growth medium was adjusted to approximately 60000 per ml of growth medium. $0 \cdot 2 \mathrm{ml}$ of this suspension, which contained sufficient numbers of VZV infected cells to give 50-100 VZV plaques per monolayer (Fig. 1), was placed in each of 10 wells of the Belco MicroSlide culture chamber (A R Horwell Ltd) and the chambers incubated for 48 hours at $35^{\circ} \mathrm{C}$. The monolayers were fixed with acetone for 10 minutes at

Table 1 Reproducibility of the immunofluorescence test: five aliquots of two positive sera tested on five separate occasions

\begin{tabular}{llc}
\hline Aliquots of sera & \multicolumn{2}{l}{ Anti-VZV IgG titres } \\
\cline { 2 - 3 } & Serum 1 & Serum 2 \\
\hline 1 & 16 & 512 \\
2 & 16 & 512 \\
3 & 16 & 1024 \\
4 & 32 & 512 \\
5 & 16 & 512 \\
\hline
\end{tabular}

room temperature. The fixed slides were stored at $-20^{\circ} \mathrm{C}$ until used. The stability of the antigen under these conditions of storage was satisfactory for up to three months.

Immunofluorescence test. Doubling dilutions of the sera ranging from 1 in 8 to 1 in 4096 were prepared in phosphate buffered saline (PBS) at $\mathrm{pH} 7 \cdot 3$. The dilutions initially examined for the presence of IgG were from 1 in 16 to 1 in 512. The presence of IgM was screened at a dilution of 1 in 8 . Further higher dilutions were tested when required.

Approximately $10 \mu \mathrm{l}$ of each of the dilutions was spread on appropriate monolayers on the slide and incubated at $37^{\circ} \mathrm{C}$ in a moist chamber for 30 minutes. The slides were washed in PBS for 15 minutes in a magnetic stirrer. The monolayers were air dried and covered with appropriately diluted antihuman IgG or IgM conjugated with fluorescein isothiocyanate $(\mathrm{Hy}-$ land Laboratories Ltd, Lorrne Laboratories Ltd). Incubation and washing were repeated as before except for an extra final wash of the slides in distilled water for 5 minutes. The slides were air dried and mounted in a glycerol mountant ${ }^{6}$ and examined with a Zeiss Standard 18UV microscope fitted with a Zeiss filter set 10 . The tests were read under a $\times 16$ Neofluar objective and $\times 10$ eyepieces.

The end point of the titration was taken as the last dilution in which cells with specific fluorescence could be clearly seen.

Reproducibility of the test. The reproducibility of the test was determined by testing aliquots of two positive sera stored at $-20^{\circ} \mathrm{C}$ on five separate occasions.

\section{Results}

Reproducibility of the test. The results showed complete agreement in titre in four of the five aliquots for each of the two sera tested. The remaining aliquot showed only a one-tube difference in titre (Table 1 ).

Levels of distribution of anti-VZV IgG. The distribution and levels of anti-VZV IgG in the sera of all the categories of patients are shown in Table 2 . The

Table 2 Distribution of levels of anti-VZV $\lg G$ in the different patient groups

\begin{tabular}{|c|c|c|c|c|c|c|c|c|}
\hline \multirow[t]{3}{*}{ Clinical diagnosis } & \multicolumn{7}{|c|}{ Number of sera } & \multirow[t]{2}{*}{ Total } \\
\hline & \multicolumn{7}{|c|}{ Anti-VZV IgG titres } & \\
\hline & \multicolumn{2}{|c|}{$\leqslant 1632$} & \multirow{2}{*}{$\frac{64}{4}$} & \multirow{2}{*}{$\begin{array}{c}128 \\
10\end{array}$} & \multirow{2}{*}{$\begin{array}{c}256 \\
26\end{array}$} & \multirow{2}{*}{$\begin{array}{c}512 \\
46\end{array}$} & $\geqslant 1024$ & \\
\hline $\mathrm{HZO}$ & 9 & 4 & & & & & 35 & 134 \\
\hline HSV ocular & 15 & 4 & 2 & 0 & 0 & 0 & 0 & 21 \\
\hline Adenovirus ocular & 84 & 18 & 15 & 7 & 0 & 0 & 0 & 124 \\
\hline Other 'viral' ocular & 46 & 9 & 12 & 2 & 0 & 2 & 0 & 71 \\
\hline
\end{tabular}


results show that 107 of the $134(80 \%)$ of the sera from patients with $\mathrm{HZO}$ had a titre of $\geqslant 256$. In comparison, only two out of a total of 216 patients $(1 \%)$ with ocular problems other than those of $\mathrm{HZO}$ had a titre of $\geqslant 256$ (Table 2).

Level of anti-VZV IgM in patients with HZO. IgM at a level of 1 in 8 was found in 6 of the 134 sera from patients with $\mathrm{HZO}$.

Cross reactivity with $H S V 1$. Sera of 27 patients with $\mathrm{HZO}$ were tested against HSV-1 antigen in addition to the VZV antigen. Twenty-one had an anti-HSV1 IgG titre of 64 or less, four had a titre of 128 , and the remaining two had a titre of 256 . In all but two samples anti-VZV. IgG titre was at least fourfold greater than the anti-HSV1 titre.

Anti VZV IgG titres and skin lesions. The results are presented in Fig. 2. Anti-VZV IgG titres increased within about four to six days of onset of skin lesions of HZO and appeared to fall to baseline levels after the second month.

\section{Discussion}

In this study a simple, practical, and reproducible serological test has been developed for the diagnosis of HZO using a single serum sample. It has been possible to make a provisional diagnosis of $\mathrm{HZO}$ with a high degree of confidence.

Previous studies evaluating immunofluorescence (IF) serological tests for the detection of antibody against VZV have used human diploid cells with a

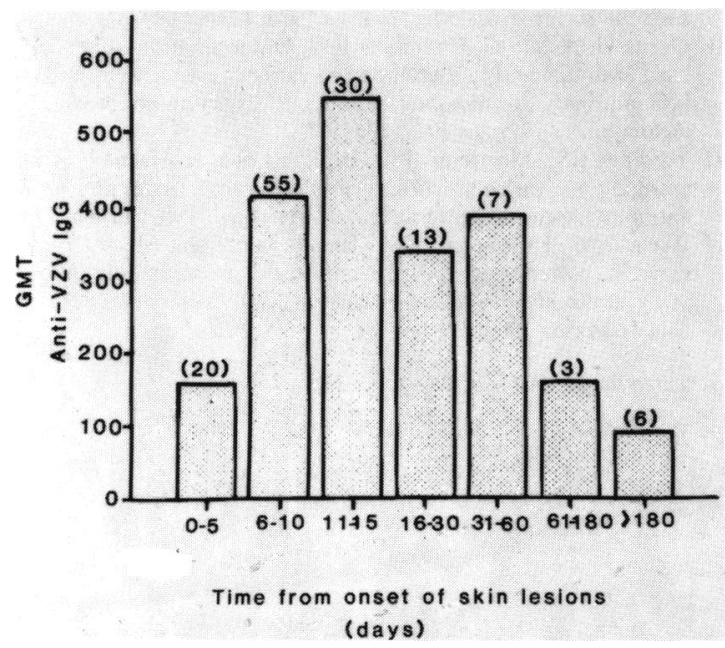

Fig. 2 Correlation between levels of anti-VZVIgG titres and time from onset of skin lesions in $\mathrm{HZO}$ patients. Each bar represents geometric mean anti-VZV IgG titres in $\mathrm{HZO}$ patients at various times after onset of skin lesions. Figures in parentheses indicate numbers of observations for each time interval. limited life span for the preparation of antigen. ${ }^{47}$ In this study we used HeLa cells, which have the advantage of being a continuous cell line. HeLa are known to be satisfactory for maintenance of VZV in serial passage and for the preparation of complement fixing antigen. ${ }^{\mathrm{x}}$

The use of fixed monolayers as antigen makes the morphology of VZV plaques well preserved: specific fluorescence was confined to the plaques or foci of VZV-infected cells which result from the cell to cell spread and was not seen in the surrounding uninfected HeLa cells (Fig. 1). This makes the end point easier to read and would explain the good reproducibility of the test (Table 1). Previous workers have used infected cell monolayers as antigen, but the methods of preparation have been cumbersome. ${ }^{47}$ The fixed antigen slides stored at $-20^{\circ} \mathrm{C}$ could be used for at least three months and thus are practical for routine use. The test is economical, since the Belco chambers make it possible to have 10 infected monolayers on the same slide.

The test showed a high degree of sensitivity and specificity in the differential diagnosis of HZO from other ocular viral infections. The results show that $80 \%$ of the 134 sera from patients with a clinical diagnosis of $\mathrm{HZO}$ had anti-VZV IgG titre of $\geqslant 256$. Such titres were found in only 2 of 216 sera from patients with a clinical diagnosis of ocular 'viral' infections. In $27(20 \%)$ of the HZO patients lower titres $(<256)$ were found. Two-thirds of these were probably due to early collection of sera because they were taken within one week of onset of rash. In addition a review of clinical diagnosis in 17 cases showed that one had a probable HSV infection and in two the diagnosis of zoster was not confirmed clinically.

Anti-VZV IgG was present in all the sera of patients with $\mathrm{HZO}$ studied here. The titres increased rapidly, usually within a week, peaked at 10 to 15 days, and appeared to fall after the second month (Fig. 2). Thus the test has an obvious advantage in cases of chronic infection or late acute cases. The number of observations after two months was small for any valid conclusion to be drawn beyond this period.

The problem of cross reactivity between VZV and HSV infections has been noted previously. ${ }^{9}$ In this study anti-VZV IgG was detected in all 21 patients with HSV ocular infections but only in low titres ranging from 16 to 64 (Table 2). Anti-HSV1 IgG was also detectable in $\mathrm{HZO}$ patients, but, again, the majority had titres in the range of up to 64 (Tables). This suggests a degree of cross reactivity between these viruses. However, the degree of cross reaction detected was not sufficient to interfere with the interpretation of the result for the diagnosis of HZO. 
Table 3 Levels of anti-VZV and anti-HSVI IgG in 27 patients with $\mathrm{HZO}$

\begin{tabular}{|c|c|c|c|}
\hline Patient & $\begin{array}{l}\text { Onset } \\
\text { (days) }\end{array}$ & Anti-VZV & Anti-HSVI* \\
\hline 1 & 12 & 2048 & 32 \\
\hline 2 & 90 & 128 & $0 \dagger$ \\
\hline 3 & 5 & 2048 & 16 \\
\hline 4 & 5 & 512 & 0 \\
\hline 5 & - & 2048 & 32 \\
\hline 6 & 14 & 512 & 0 \\
\hline 7 & 42 & 1024 & 64 \\
\hline 8 & 21 & 512 & 0 \\
\hline 9 & - & 64 & 16 \\
\hline 10 & - & 512 & 16 \\
\hline 11 & $6 \mathrm{yr}$ & 32 & 16 \\
\hline 12 & 5 & 2048 & 32 \\
\hline 13 & 14 & 1024 & 128 \\
\hline 14 & 12 & 512 & 64 \\
\hline 15 & 8 & 2048 & 32 \\
\hline 16 & 12 & 1024 & 64 \\
\hline 17 & 15 & 1024 & 0 \\
\hline 18 & 10 & 2048 & 0 \\
\hline 19 & 28 & 512 & 128 \\
\hline 20 & 6 & 128 & 256 \\
\hline 21 & 11 & 512 & 128 \\
\hline 22 & 50 & 1024 & 64 \\
\hline 23 & 7 & 512 & 16 \\
\hline 24 & 1 & 16 & 0 \\
\hline 25 & 28 & 1024 & 256 \\
\hline 26 & 12 & 1024 & 128 \\
\hline 27 & 10 & 2048 & 16 \\
\hline
\end{tabular}

* Determined by using an indirect microimmunofluorescence test. ${ }^{5}$ $\dagger 0=<16$.

Cradock-Watson et al..$^{4}$ found IF to be more sensitive than the complement fixation test in detecting VZV antibodies, but even in their study the range of these antibodies in HSV patients was relatively low (titres 8 to 64$)$.

Anti-VZV IgM was found in only six of the 134 patients with HZO. Various authors have suggested that the presence of IgM is uncommon in zoster, which is usually considered a secondary VZV infection. ${ }^{910}$ However, others have found $\operatorname{Ig} M$ in acute varicella or zoster by the IgM capture radioimmunoassay (RIA) test, ${ }^{11}$ IF,${ }^{4}$ and RIA.${ }^{12}$ The differences in IgM detection between this study and that of Cradock-Watson et al., who found IgM in $75 \%$ of 55 patients with herpes zoster, is difficult to explain. However, the difference may be related to the differences in methods and patient selection.

The authors are grateful to the staff of the Zoster Clinic and the Keratoconjunctivitis Clinic for the collection of specimens. The study was supported by a grant from the DHSS administered by Moorfields Eye Hospital.

\section{References}

1 Marsh RJ. Herpes zoster keratitis. Trans Ophthalmol Soc UK 1973; 93: 181-92.

2 Frey MH, Stcinberg SP, Gershon AA. Rapid diagnosis of varicella zoster virus infections by counter immunoclectrephoresis. J Infect Dis 1981; 143: 274-80.

3 Schmidt NJ, Ho HH, Lennette EH. Comparative sensitivity of human fetal diploid kidney cell strains and monkey kidncy cell cultures for isolation of certain viruses. Am J Clin Pathol 1965; 43: 297-301.

4 Cradock-Watson JE, Margaret K, Ridchalgh S. Specific immunoglobulin responses after varicella and herpes zoster. $J$ Hyg (Lond) 1979; 82: 319-36.

5 Forsey T, Darougar S. Indirect immunofluorescence test for detecting type specific antibodics to herpes simplex virus. J Clin Pathol 1980; 33: 171-6.

6 Johnson GD, Davidson RS, McNamec KC, Russel G, Goodwin D, Holbrow EH. Fading of immunofluorescence during microscopy: a study of the phenomenon and its remedy. J Immunol Methods 1982; 55: 231-42.

7 Campbell-Benzic, Heath RB, Ridehalgh MKS, CradockWatson JE. A comparison of immunofluorescence and radioimmunoassay for detecting antibody to varicella zoster. $J$ Virol Methods 1983; 6: 135-40.

8 Svedmyr A. Varicella virus in HcLa cells. Arch Ges Virusforsch 1965; 17: 495-503.

9 Schmidt NJ, Lennette EH. Neutralizing antibody responses to varicella zoster virus. Infect Immun 1975; 12: 606-13.

10 Gerna G, Achilli G, Chambers RW. Determination of neutralizing antibody and IgG antibody to varicella zoster virus and of IgG antibody to membrane antigens by immunoperoxidase technique. J Infect Dis 1977; 135: 975-9.

11 Tredder RS. Mortimer PP, Bridget-Lord R. Detection of antibody to varicella zoster virus by competitive and IgM antibody capture immunoassay. $J^{\prime}$ Med Virol 1981; 8: 89-101.

12 Arvin AM, Koropchak CM. Immunoglobulins $M$ and $G$ to varicella zoster' virus measured by solid phase radioimmunoassay: antibody responses to varicella and zoster infections. $J$ Clin Microbiol 1980; 12: 367-74.

Accepted for publication 31 October 1985. 